\title{
Optimizing flavonoid-rich Quranic Mixed Food (QMF) formulation with simplex-centroid mixture design
}

\author{
${ }^{1,2}$ Salbi, N.M., ${ }^{1,3 *}$ Muhammad, N. and ${ }^{1}$ Abdullah, N. \\ ${ }^{1}$ Department of Technology and Natural Resources, Faculty of Applied Sciences and Technology, Universiti \\ Tun Hussein Onn Malaysia, UTHM Pagoh Campus, Pagoh Education Hub, KM 1, Jalan Panchor, 84600 \\ Muar, Johor, Malaysia \\ ${ }^{2}$ Department of Chemical and Food Technology, Politeknik Tun Syed Nasir Syed Ismail, Pagoh Education \\ Hub, KM 1, Jalan Panchor, 84600 Muar, Johor, Malaysia \\ ${ }^{3}$ Institut Ahli Sunnah Wal Jamaah, Universiti Tun Hussein Onn Malaysia, 86400 Parit Raja, Batu Pahat \\ Johor, Malaysia
}

\begin{abstract}
Article history:
Received: 27 August 2020

Received in revised form: 1

October 2020

Accepted: 17 November 2020

Available Online: 27

February 2021
\end{abstract}

Keywords:

Flavonoid,

Optimization,

Quranic food,

Simplex centroid design

DOI:

https://doi.org/10.26656/fr.2017.5(2).470

\begin{abstract}
Quranic food, which defines as the food mentioned in the Holy Quran has gain attention as a functional food to prevent disease in the current era. The food had high potential as an excellent ingredient for the development of nutraceutical products. Flavonoid is one of the phytochemicals in Quranic food that contribute to their therapeutic properties. Unfortunately, there is less study on the health properties of Quranic food mixture that lead to misunderstanding of the mixture of Quranic food. A paramount concern regarding the addition of multiple bioactive ingredients into a product is the possibility of interaction among elements may result in degradation of the ingredient, and the functionality could be reduced or improved. Therefore, this study was aimed to optimize the flavonoid content of Quranic Mixed Food (QMF) containing dates, raisins, pomegranates, figs, and honey. Consequently, the special cubic model of simplex centroid design was employed as it was the most reliable and can be utilized in the optimization process as the $p$-value was significant, and the lack of fits was not substantial. The simplex centroid method had successfully optimized the QMF formulation. To conclude, the optimized formulation of flavonoid-rich QMF containing 42.88\% raisins, 42.88\% pomegranates, 13.97\% honey, $0.17 \%$ dates, and $0.11 \%$ figs.
\end{abstract}

\section{Introduction}

Health and wellness are among the core segments of the fast-moving consumer good, with the ever-increasing health consciousness among consumers around the world (Nazir et al., 2019). At present, nature-based nutraceutical food products with targeted physiological functions are the heart of research and development activities (De Vries et al., 2018). In conjunctions to those matters, there were several studies conducted on exploring the unique medicinal properties and chemical constitution of food mentioned in the Holy Quran which is known as Quranic food (Sheikh and Dixit, 2015). It cannot be denied that Quranic food had therapeutic effects and used in preventive medicine for decades (Western et al., 2009). The popular Quranic food and known to had benefits to health are dates, raisins, honey, pomegranates, and figs (Muhammed and Shamsi, 2016; Al-Habsi and Al-Khusaibi, 2018). Flavonoid is the polyphenol in those mentioned foods reported to have the ability to be a biological modifier that gives health benefits to consumers (Rahmani et al., 2014; Asaduzzaman et al., 2015; Azahar et al., 2017). Unfortunately, there is less study on the health properties of Quranic food mixture that lead to misunderstanding of the mixture of Quranic food (Muhammed and Shamsi, 2016). Significant concern regarding the addition of multiple bioactive ingredients into a product is the possibility of interaction among ingredients may result in degradation of the ingredient, and the functionality could be reduced or improved (Sun-Waterhouse, 2011). Hence, the systematic optimization method on multiple natural ingredient interaction research concerning certain food content will help to enlighten the understanding of those matters.

Optimization of the formulation can be conducted by any design expert software (Wass, 2001), as it involves 
three main steps which are analyzing to select of the fitted model, optimization (Adiba et al., 2011; Salem et al., 2011; Bose et al., 2013; Saifullah et al., 2016; Azahar et al., 2017) and validation (Banala et al., 2013; Rahim et al., 2018). The simplex centroid method is a collection of statistical and mathematical techniques that useful in developing, improving, and optimizing the mixture (Patel et al., 2017). Understanding the effects of independent variables and the interactions between variables and response can be achieved through analysis of variance (ANOVA) of the mix (Amalina et al., 2018). In the optimization technique, selecting the best model is the primary procedure to determine the desirability function of multiple responses. The desirability of the model can be determined by analyzed the $F$ value, lack of fits test, $\mathrm{F}$ statistics, multiple correlation coefficient $\left(\mathrm{R}^{2}\right)$ test and desirability value (Marasini et al., 2012).

In accordance with the development of the Quranic Mixed Food (QMF) product, there is less available research on the flavonoid content of that Quranic food when mixed. On the other hand, the selection of functional ingredients that had specific phytochemical properties is the primary challenge being faced in formulating nutraceutical products as the results of increasing demand from the consumer for more variety and optimize the benefits of food (Ververidis et al., 2007). Therefore, the simplex centroid design method can be utilized in this study to develop the optimized formulation. Our study aimed to employ the simplex centroid design of Design Expert in optimizing the formulation of QMF. The optimization goal was to develop the formulation of QMF with an optimized total flavonoid content (TFC). The optimized formulation will be utilized as an ingredient in nutraceutical food development in the future.

\section{Materials and methods}

\subsection{Chemical and instrument}

Aluminium chloride $\left(\mathrm{AlCl}_{3}\right)$, methanol $\left(\mathrm{CH}_{3} \mathrm{OH}\right)$, potassium acetate $\left(\mathrm{CH}_{3} \mathrm{CO}_{2} \mathrm{~K}\right)$, and quercetin $\left(\mathrm{C}_{15} \mathrm{H}_{10} \mathrm{O}_{7}\right)$ were purchased from Merck Germany. The instrument used was Ultraviolet-visible (UV-Vis) spectrophotometer (T60 U, PerkinElmer, USA), laboratory juice maker (KEA0236, Alpha, China), and vacuum oven (VD 23, Binder, Canada).

\subsection{Collection and preparation of food powder}

All raw materials, dried dates, dried raisins, pomegranate fruit, dried fig, and honey, were purchased from the local market in Johor, Malaysia. Pomegranate fruit was washed and peel then juice was collected by juice maker. All dried fruit (fig, date, and raisin) were soaked in distilled water in ratio $1: 1$ for $24 \mathrm{hrs}$ at $4 \pm 2^{\circ} \mathrm{C}$ before processed by the following method by Pourghayoumi et al. (2016). All the juices were filtered using sterile Whatman No. 1 filter paper to get a clear juice. Consequently, fruit juice was mixed as the proportion suggested by experimental design (Table 1) and dried at $35 \pm 2{ }^{\circ} \mathrm{C}$ for $16 \mathrm{hrs}$ to produce powder (Ramamoorthy and Bono 2007) and stored at $-15 \pm 2{ }^{\circ} \mathrm{C}$ before further analysis.

\subsection{Experimental design}

The optimization process was conducted by following the method of Rahim et al. (2018) with modification. The simplex centroid design was used as the experimental design. The percentage of dates, raisins, pomegranates, figs, and honey is chosen as independent variables while total flavonoid content was assigned as the dependent variable. The optimization process is conducting by changing the percentage of independent variables concurrently and keeping their total percentage constant (100). The simplex-centroid mixture design was chosen for the experiments due to the independent variables have an equal variety, which between $0-100$, and there had been no constraints on the design space. The simplex refers to the geometry shape of a triangle in two-dimensions while tetrahedron in three-dimensions. The simplex-centroid is extra uniformly allotted within the indoors of the triangle and helps to come across the curvature of the reaction surface. All proportions of all independent variables in each mixture were sum to $100 \%$ for a mixture load of the desired amount.

\subsection{Response analysis}

The response of this study was total flavonoid content (TFC) that was determined spectrophotometrically according to the Dowd method describe by Ramamoorthy and Bono (2007) with a slight modification. The $1 \mathrm{~mL}$ of sample solution $(0.4 \mathrm{mg} / \mathrm{mL})$ was taken and mixed well with $3 \mathrm{~mL}$ of methanol. Then, $0.2 \mathrm{~mL}$ of $10 \% \mathrm{AlCl}_{3}$ and $0.2 \mathrm{~mL}$ of $\mathrm{CH}_{3} \mathrm{CO}_{2} \mathrm{~K}$ in $1 \mathrm{M}$ were added to the mixture. The solution was held at the dark condition for 30 mins before absorption readings were taken at $420 \mathrm{~nm}$ against the blank. The TFC was determined using a standard curve with quercetin $(0,10$, 50,100 , and $200 \mu \mathrm{g} / \mathrm{mL}$ ) as the standard. TFC was express as $\mathrm{mg}$ of quercetin equivalents $(\mathrm{QE}) / \mathrm{mg}$ of sample.

\subsection{Statistical analysis and optimization}

Optimization and statistical analysis were constructed by using a Simplex Centroid design of Design-Expert Software 6.0.3 models. The data were analyzed by analysis of variance (ANOVA), followed by 
Table 1. Design layout and experimental results for TFC

\begin{tabular}{|c|c|c|c|c|c|c|}
\hline \multirow{2}{*}{ RUN } & \multicolumn{5}{|c|}{ Independence Variable Proportion (\%) } & \multirow{2}{*}{$\frac{\text { Response }}{\mathrm{TFC}(\mu \mathrm{g} \mathrm{QE} / \mathrm{mg})}$} \\
\hline & Date & Raisin & Pomegranate & Fig & Honey & \\
\hline 1 & 25 & 25 & 25 & 25 & 0 & $11.05 \pm 0.4^{\text {ghijkl }}$ \\
\hline 2 & 0 & 0 & 0 & 100 & 0 & $8.06 \pm 0.6^{\mathrm{klmn}}$ \\
\hline 3 & 0 & 0 & 50 & 50 & 0 & $13.04 \pm 0.9^{\text {cdefghi }}$ \\
\hline 4 & 0 & 33.33 & 0 & 33.33 & 33.33 & $4.86 \pm 0.3^{\text {nop }}$ \\
\hline 5 & 0 & 50 & 50 & 0 & 0 & $22.38 \pm 2.5^{\mathrm{a}}$ \\
\hline 6 & 33.33 & 0 & 33.33 & 0 & 33.33 & $9.45 \pm 2.0^{\mathrm{ijk} k \mathrm{mn}}$ \\
\hline 7 & 0 & 0 & 50 & 50 & 0 & $13.04 \pm 0.9^{\text {cdefghi }}$ \\
\hline 8 & 100 & 0 & 0 & 0 & 0 & $13.21 \pm 0.9^{\text {cdefghi }}$ \\
\hline 9 & 0 & & 100 & 0 & 0 & $17.08 \pm 0.3^{\mathrm{bc}}$ \\
\hline 10 & 20 & 20 & 20 & 20 & 20 & $11.11 \pm 1.8^{\text {ghijkl }}$ \\
\hline 11 & 33.33 & 0 & 33.33 & 33.33 & 0 & $16.63 \pm 1.5^{\mathrm{cde}}$ \\
\hline 12 & 10 & 10 & 60 & 10 & 10 & $11.99 \pm 1.5^{\text {defghij }}$ \\
\hline 13 & 50 & 50 & 0 & 0 & 0 & $16.69 \pm 1.0^{\mathrm{cd}}$ \\
\hline 14 & 33.33 & 33.33 & 33.33 & 0 & 0 & $9.45 \pm 2.0^{\mathrm{ijk} k \mathrm{mn}}$ \\
\hline 15 & 10 & 60 & 10 & 10 & 10 & $11.94 \pm 2.3^{\text {defghij }}$ \\
\hline 16 & 0 & 50 & 0 & 0 & 50 & $8.51 \pm 2.4^{\mathrm{jklmno}}$ \\
\hline 17 & 0 & 50 & 0 & 50 & 0 & $9.45 \pm 2.0^{\mathrm{ijklmn}}$ \\
\hline 18 & 25 & 0 & 25 & 25 & 25 & $14.31 \pm 0.2^{\text {cdefgh }}$ \\
\hline 19 & 0 & 50 & 0 & 0 & 50 & $6.96 \pm 2.4^{1 \mathrm{mnop}}$ \\
\hline 20 & 50 & 50 & 0 & 0 & 0 & $14.42 \pm 1.2^{\text {cdefg }}$ \\
\hline 21 & 33.33 & 0 & 0 & 33.33 & 33.33 & $11.11 \pm 1.8^{\text {ghijkl }}$ \\
\hline 22 & 25 & 25 & 25 & 0 & 25 & $11.66 \pm 1.1^{\text {fghijk }}$ \\
\hline 23 & 50 & 0 & 50 & 0 & 0 & $11.16 \pm 0.9^{\text {fghijkl }}$ \\
\hline 24 & 33.33 & 33.33 & 0 & 33.33 & 0 & $12.60 \pm 1.5^{\text {cdefghij }}$ \\
\hline 25 & 10 & 10 & 10 & 10 & 60 & $4.80 \pm 1.5^{\mathrm{nop}}$ \\
\hline 26 & 0 & 0 & 0 & 0 & 100 & $4.19 \pm 0.7^{\mathrm{op}}$ \\
\hline 27 & 0 & 0 & 50 & 0 & 50 & $6.52 \pm 1.3^{\text {mnop }}$ \\
\hline 28 & 10 & 10 & 10 & 60 & 10 & $10.39 \pm 1.7^{\text {ghijkl }}$ \\
\hline 29 & 50 & 0 & 0 & 0 & 50 & $6.96 \pm 2.0^{1 \mathrm{mnop}}$ \\
\hline 30 & 0 & 0 & 0 & 50 & 50 & $2.04 \pm 1.9^{p}$ \\
\hline 31 & 60 & 10 & 10 & 10 & 10 & $15.58 \pm 2.0^{\text {bcdef }}$ \\
\hline 32 & 0 & 0 & 33.33 & 33.33 & 33.33 & $3.80 \pm 1.3^{\mathrm{op}}$ \\
\hline 33 & 0 & 33.33 & 33.33 & 0 & 33.33 & $19.62 \pm 2.8^{\mathrm{ab}}$ \\
\hline 34 & 33.33 & 33.33 & 0 & 0 & 33.33 & $11.71 \pm 1.6^{\text {efghijk }}$ \\
\hline 35 & 0 & 0 & 50 & 0 & 50 & $6.52 \pm 1.3^{\mathrm{mnop}}$ \\
\hline 36 & 50 & 0 & 0 & 50 & 0 & $19.67 \pm 2.0^{\mathrm{ab}}$ \\
\hline 37 & 25 & 25 & 0 & 25 & 25 & $8.51 \pm 0.5^{\mathrm{jklmno}}$ \\
\hline 38 & 0 & 100 & 0 & 0 & 0 & $13.98 \pm 0.4^{\text {cdefghi }}$ \\
\hline 39 & 0 & 33.33 & 33.33 & 33.33 & 0 & $9.56 \pm 0.3^{\text {ghijklm }}$ \\
\hline 40 & 0 & 25 & 25 & 25 & 25 & $11.60 \pm 0.4^{\text {fighijk }}$ \\
\hline 41 & 50 & 0 & 0 & 50 & 0 & $16.08 \pm 0.7^{\text {cdef }}$ \\
\hline
\end{tabular}

Values are expressed as mean \pm SD. Values with different superscripts within the column are significantly different from each other $(\mathrm{p} \leq 0.05)$

optimization through a linear, quadratic and special cubic models were used for a variety of response as a function of significant interaction effect $(p<0.05)$ between the proportion with acceptable determination coefficients $\left(\mathrm{R}^{2}>0.90\right)$. The differences were determined by the Turkey LSD test and defined as statistically significant at $p<0.05$.

\section{Results and discussion}

Model fitting and performance analysis statistical result discussed how the best model could be selected while content modelling, proportion optimization, and validation process explain the details of optimized QMF.

\subsection{Analysis of response}

Table 1 shows the TFC of all formulation of QMF 
generated by Design-Expert software (version 6, USA, 2000). The TFC was express as $\mathrm{mg}$ of quercetin equivalents $(\mathrm{QE}) / \mathrm{mg}$ of sample. It is determined quantitatively with quercetin standard curve (Figure 1) by the equation $\mathrm{y}=2.0399 \mathrm{x}+0.003, \mathrm{R}^{2}=0.98$. Quercetin was selected as standard as it is reported as the main type of flavonoids presented at high value in Quranic food (Slatnar et al., 2011; Marquez et al., 2012; Al-Habsi and Al-Khusaibi, 2018). The data shows that the highest $(p<0.05)$ TFC content for the single component is $17.07 \pm 0.3 \mu \mathrm{g} \mathrm{QE} / \mathrm{mg}$ (pomegranate), and the lowest $(p<0.05)$ TFC content is $4.20 \pm 0.7 \mu \mathrm{g} \mathrm{QE} / \mathrm{mg}$ (honey). Previous studies have demonstrated that pomegranates (Poyrazoğlu et al., 2002) and raisins (Marquez et al., 2012) had high flavonoid content compared to dates (Harnly et al., 2006), figs (Slatnar et al., 2011) and honey (Khalil et al., 2011). Table 1 also showed that the TFC for the $5^{\text {th }}$ run $(50 \%$ raisin: $50 \%$ pomegranate) exhibited the highest $(p<0.05)$ TFC value $(22.38 \pm 2.5 \mu \mathrm{g} \mathrm{QE} / \mathrm{mg})$. In contrast, the $30^{\text {th }}$ run $(50 \%$ date: $50 \%$ honey) had the lowest $(p<0.05)$ content of TFC $(2.04 \pm 0.2 \mu \mathrm{g} \mathrm{QE} / \mathrm{mg})$. Previous research had reported that there was no scientific data on the relationship between QMF and TFC. The single most striking observation to emerge from the data comparison was the proportion of mixture with raisin and pomegranate might improve the flavonoid content of the mixture. In contra, the mixture with honey may not improve the flavonoid content of the mixture. These results support the idea of Hidalgo, Sánchez-Moreno and de Pascual-Teresa (2010) that flavonoid-flavonoid interaction may give synergic or antagonistic effect. The effect of variables on the flavonoid contents is further discussed in the modelling equation and mixture optimization.

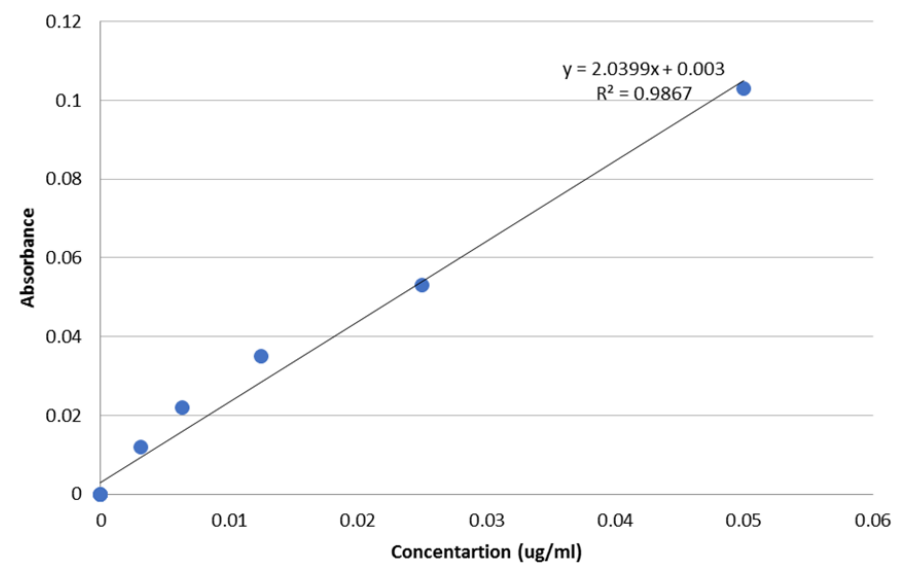

Figure 1. Calibration curve of Quercetin standard

\subsection{Model fitting and performance analysis}

Table 2 indicates the ANOVA analysis of the model, showing the responses were fitted to linear, quadratic, and special cubic models. The mixture model coefficients were validated by ANOVA of the response variable for linear, quadratic, and specific cubic models. The ANOVA results were calculated based on 95\% confidence intervals. These findings were used to determine the best-fitted model for five independence variables (proportion of dates, raisins, pomegranates, figs, and honey). The performance of the model was evaluated by using variation within the samples (Fstatistics), lack of fit test, and multiple correlation coefficient $\left(\mathrm{R}^{2}\right)$ tests. Based on the result, the large amount of model F-value implies there is less probability of different variations of result to occur. It showed that linear, quadratic, and special cubic model is highly significant when the probability value is low $(p<0.0001)$ indicating that the model can be utilized in determining the interaction effect of variables and response.

Comparing the probability $\mathrm{F}$ value of lacks fit, the specific cubic model is the more desirable model to be selected as it is not significant. Furthermore, the performance of the models also checked by the determination of $\mathrm{R}^{2}$, coefficient of variation $(\mathrm{CV})$, and adequate precision. The $\mathrm{R}^{2}$ value signifies the measure of the amount of variation around the mean explained by the model. From Table 2, the $\mathrm{R}^{2}$ for the special cubic model is higher compared to linear and quadratic. According to Azahar et al. (2017), the closer the $\mathrm{R}^{2}$ value to 1.0 , the better and significant the model fits the actual data. The CV for special cubic shows the lowest value, which indicates better reliability of the model. Another important finding was the adequate precision to measure the signal to noise ratio. The adequate precision of the special cubic value was highest as stated in Table 2 (16.810) relative to other models; linear (12.977) and quadratic (10.929). This suggests that the most accurate model for use as an optimization process was the special cubic model.

\subsection{Modelling of TFC content}

The model fitting and performance analysis had identified that special cubic is the best model to be selected. The empirical regression of special cubic model of their relationship between responses and the five

Table 2. ANOVA Analysis Result

\begin{tabular}{lcccccc}
\hline \multicolumn{1}{c}{ Model } & F value & $\begin{array}{c}\text { Prod }>\text { F } \\
\text { value }\end{array}$ & $\begin{array}{c}\text { Lack of fit- } \\
\text { Prob }>\text { F } \\
\text { value }\end{array}$ & $\mathrm{R}^{2}$ & $\mathrm{CV}$ & $\begin{array}{c}\text { Adequate } \\
\text { Precision }\end{array}$ \\
\hline Linear & 9.69 & $<0.0001$ & 0.0112 & 0.5186 & 31.56 & 12.977 \\
Quadratic & 5.93 & $<0.0001$ & 0.0243 & 0.7616 & 26.14 & 10.929 \\
Special Cubic & 14.18 & $<0.0001$ & 0.2422 & 0.9551 & 14.46 & 16.81 \\
\hline
\end{tabular}


variables for total flavonoid contents could be expressed as below:

$\mathrm{TFC}=2.67 * \mathrm{~A}+2.65^{*} \mathrm{~B}+3.24 * \mathrm{C}+1.57 * \mathrm{D}+$ $0.66^{*} \mathrm{E}+2.46^{*} \mathrm{~A} * \mathrm{~B}-3.40^{*} \mathrm{~A} * \mathrm{C}+5.46^{*} \mathrm{~A} * \mathrm{D}-$ $1.44 * \mathrm{~A} * \mathrm{E}+5.44^{*} \mathrm{~B} * \mathrm{C}-1.35^{*} \mathrm{~B} * \mathrm{D}-0.97 * \mathrm{~B} * \mathrm{E}+$ $0.16^{*} \mathrm{C}^{*} \mathrm{D}-3.26^{*} \mathrm{C} * \mathrm{E}-3.59^{*} \mathrm{D} * \mathrm{E}-43.41^{*} \mathrm{~A}^{*} \mathrm{~B} * \mathrm{C}$ - 16.54*A*B*D - 1.65*A*B*E + 19.96*A*C*D + 15.96*A*C*E + 15.43*A* D*E - 25.25*B*C*D + $39.73 * \mathrm{~B} * \mathrm{C} * \mathrm{E}-2.38 * \mathrm{~B} * \mathrm{D} * \mathrm{E}-8.93 * \mathrm{C} * \mathrm{D} * \mathrm{E}$

Where $\mathrm{A}$ is dates, $\mathrm{B}$ is raisin, $\mathrm{C}$ is pomegranate, $\mathrm{D}$ is fig, and $\mathrm{E}$ is honey. A positive sign in each equation represents a synergistic effect of the variables. On the other hand, a negative sign represents an antagonistic effect of the variables (Azahar et al., 2017). From Equation (1) identified that mixture of date-raisin, datefig, raisin-pomegranate, pomegranate-fig, datepomegranate-fig, date-pomegranate-honey, date-fighoney, and raisin-pomegranate-honey show synergic effect. Contrarily, date-pomegranate, date-honey, raisinfig, raisin-honey, pomegranate-honey, fig-honey, dateraisin-pomegranate, date-raisin-fig, date-raisin-honey, raisin-pomegranate-fig, raisin-fig-honey, and pomegranate-fig-honey show antagonistic effect. These results agree well with the argument by Sun-Waterhouse (2011), and Hidalgo et al. (2010) on there is the possibility of interaction among ingredients may result in degradation of the ingredient functional properties. This research is the first step towards a more profound understanding of the interaction of selected ingredients toward the functional properties.

\subsection{Mixture proportion optimization}

The desirability function was calculated based on the ratio in the range (0-100) of all factors (proportion of dates, raisins, pomegranates, figs, and honey) and the maximum output of response (TFC). It can be observed from the comparison of different scatter plot of the model (Figure 2), the maximum desirability value 1.0 achieved by the specific cubic model (a) followed by 0.91 for the quadratic model (b) and, lastly, 0.7 for the linear model (c). The desirability near 1.00 is the most acceptable (Arunkumar, 2009) for the optimization of the mixture.

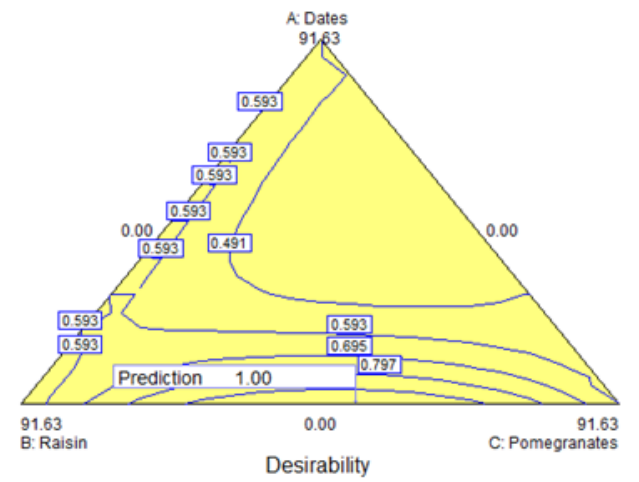

This result further confirms that special cubic is the most acceptable model for optimization. Then, an exact depiction of the variables proportion and corresponding desirability of the optimized model was shown in Figure 3.

Referring to the contour plot, X1 (pomegranate), X2 (raisin), and X3 (date) are the most factors that influence the optimizing of TFC (Figure 3). It is evident from this study that the factors (date, raisin, pomegranate, fig, and honey) would interact with each other and, in turn, affect the flavonoids content differently. It identified that the pomegranate, raisin, and date were the most significant factors in determining the optimum flavonoid content compared to fig and honey. According to the previous report (Poyrazoğlu et al., 2002; Harnly et al., 2006; Khalil et al., 2011; Slatnar et al., 2011; Marquez et al., 2012) which is also in line with this study, the flavonoid content of pomegranate, raisin, and date is higher as compared to fig and honey. In this study, all five factors

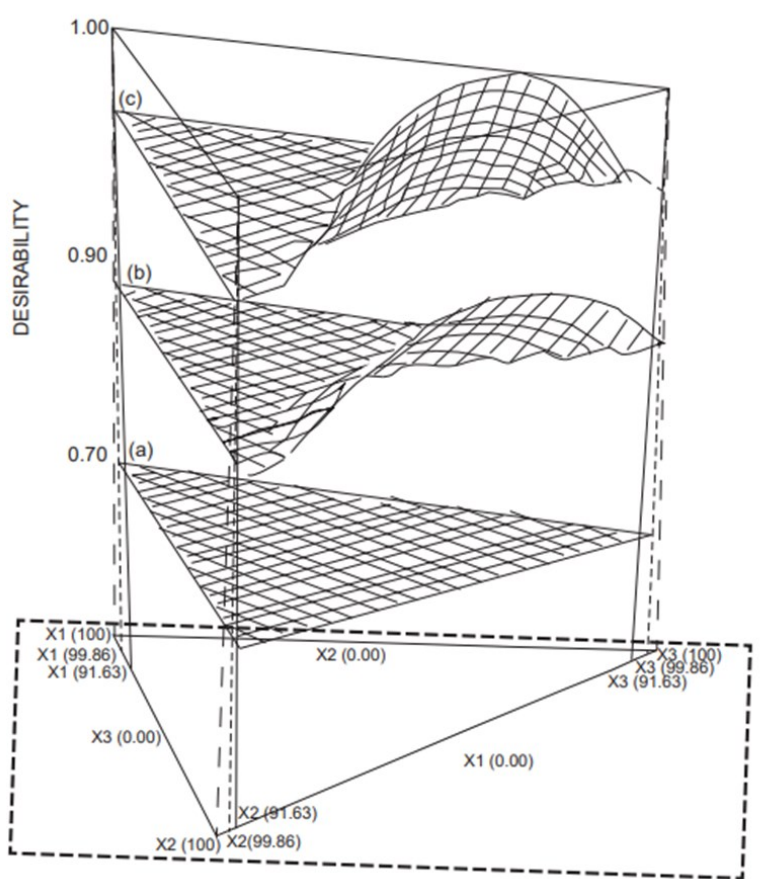

Figure 2. Comparable scatter plots of the desirability function for three different models; (a) specific cubic model, (b) quadratic model, and (c) linear model.

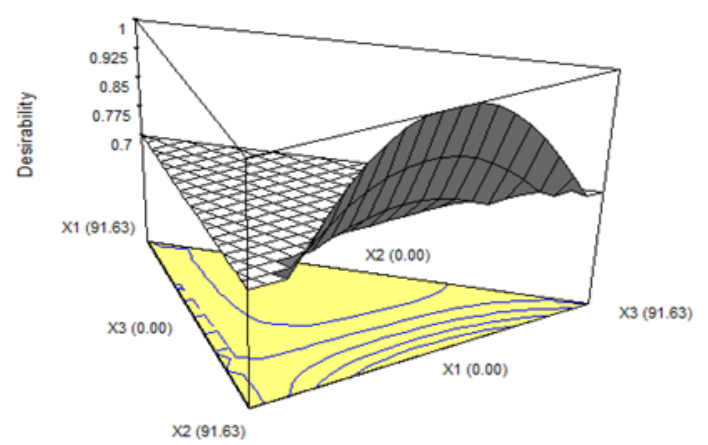

Figure 3. Mixture contour (left) and scatter (right) plots for TFC 
were selected due to their individual properties that high in flavonoid content (Slatnar et al., 2011; Marquez et al., 2012; Al-farsi et al., 2018) which contribute to the therapeutic properties. Thus, increasing the proportion of pomegranate and raisin simultaneously, as shown in the contour plot, will help in optimizing the flavonoid content of QMF formulation, which shows the desirability value is one. A possible explanation for this is that individual pomegranate and raisin had high flavonoid content as compared to honey, then it shows a synergistic effect on the response.

\subsection{Validation of model}

Previously optimization analysis, ten mixture suggested for the specific cubic model obtained using Design-Expert software. However, only one mixture ( $0.17 \%$ date, $42.88 \%$ raisin, $42.88 \%$ pomegranate, $0.11 \%$ fig, and $13.97 \%$ honey) with the highest desirability (1.00) were selected for the validation process. Finally, to confirm the validity of the optimal factors and predicted response calculated, three batches of selected optimized formulation were prepared and analyzed. The predicted response value is $22.83 \mu \mathrm{g} \mathrm{QE} / \mathrm{mg}$ while the experimental value is $23.87 \mu \mathrm{g} \mathrm{QE} / \mathrm{mg}$. The bias between the predicted and experimental value is $4.36 \%$. The bias value is below than $10 \%$ which acceptable and confirms that the model is validated. Thus, indicating the success of simplex centroid design used to the optimization of the Flavonoid-rich Quranic Mixed Food formulation.

\section{Conclusion}

The special cubic model is selected as the best model for optimizing the flavonoid-rich QMF as it satisfied all tests conducted by software. The model had better fitness compared to the linear and quadratic models. In addition, the equation represents a more detailed interaction on their response relationship with the five variables for total flavonoid content. Also, the highest desirability (1.00) and the combination of all variables to get the maximum flavonoid content. The optimized flavonoidrich QMF formulation consist of $42.88 \%$ raisins, $42.88 \%$ pomegranates, $13.97 \%$ honey, $0.17 \%$ dates, and $0.11 \%$ figs. The main factors that influence the flavonoid content of the mixture were pomegranates and raisins. Thus, the optimized formulation can be used as an ingredient in developing food or nutraceutical products in the future.

\section{Conflict of interest}

The authors declare no conflict of interest.

\section{Acknowledgements}

This work is funded by the Malaysia Ministry of Higher Education (MOHE) under Fundamental Research Grant Scheme (FRGS), Vote No 1646 (FRGS/1/2017/ WAB11/UTHM/03/1), and Hadiah Latihan Persekutuan $(H L P)$ with Cuti Belajar Bergaji Penuh (CBBP) for the funding of $\mathrm{PhD}$ study of the author at Universiti Tun Hussein Onn Malaysia. Special thanks to Universiti Tun Hussein Onn Malaysia for having provided facilities for carrying out this research.

\section{References}

Adiba, B.D., Salem, B., Nabil, S. and Abdelhakim, M. (2011). Preliminary characterization of food tablets from the date (Phoenix dactylifera L.) and spirulina (Spirulina sp.) powders. Powder Technology, 208(3), 725-730.

https://doi.org/10.1016/

j.powtec.2011.01.016

Al-farsi, K.A., Al-habsi, N.A., Al-khusaibi, M. and Sciences, M. (2018). Antioxidant potential properties of date product: A concise update. Canadian Journal of Clinical Nutrition, 6(2), 84-104. https:// doi.org/10.14206/canad.j.clin.nutr.2018.02.08

Amalina, N., Abu Bakar, M.F., Kormin, F., Linatoc, A. and Mohamed, M. (2018). Application of statistically simplex-centroid mixture design to optimize the TPC and TFC on the proportion of polyherbal formulation used by Jakun Women. Journal of Engineering and Applied Sciences, 13 (Special Issue 9), 6996-7002. https:// doi.org/10.3923/jeasci.2018.6996.7002

Arunkumar, N. (2009). Exploring novel uses of eutectic mixture in the formulation of pharmaceutical dosage forms. Retrieved from http://ir.inflibnet.ac.in:8080/ jspui/bitstream/10603/48508/15/15_publications.

Asaduzzaman, M., Rahman, M.S., Munira, S., Rahman, M., Islam, M.M., Mahadi, H. and Islam, M. (2015). Analysis of biochemical composition of honey and its antioxidant, phytochemical and antibacterial properties. Journal of Biomedical and Pharmaceutical Research, 4(4), 69-81.

Azahar, N.F., Gani, S.S.A. and Mokhtar, N.F.M. (2017). Optimization of phenolics and flavonoids extraction conditions of Curcuma Zedoaria leaves using response surface methodology. Chemistry Central Journal, 11(1), 96. https://doi.org/10.1186/s13065017-0324

Banala, V.T., Srinivasan, B., Rajamanickam, D., Basappa Veerbadraiah, B. and Varadarajan, M. (2013). Statistical optimization and in vitro evaluation of metformin hydrochloride asymmetric membrane capsules prepared by a novel 
semiautomatic manufacturing approach. ISRN Pharmaceutics, 2013, 719196. https:// doi.org/10.1155/2013/719196

Bose, A., Wong, T.W. and Singh, N. (2013). Formulation development and optimization of sustained release matrix tablet of Itopride $\mathrm{HCl}$ by response surface methodology and its evaluation of release kinetics. Saudi Pharmaceutical Journal, 21 (2), 201-213. https://doi.org/10.1016/ j.jsps.2012.03.006

De Vries, H., Axelos, M.A.V., Sarni-Manchado, P. and O'Donohue, M. (2018). Meeting new challenges in food science technology: The development of complex systems approach for food and biobased research. Innovative Food Science and Emerging Technologies, 46, 1-6. https://doi.org/10/1016/ j.ifset.2018.04.004.

Harnly, J.M., Doherty, R.F., Beecher, G.R., Holden, J.M., Haytowitz, D.B., Bhagwat, S. and Gebhardt, S. (2006). Flavonoid content of US fruits, vegetables, and nuts. Journal of Agricultural and Food Chemistry, 54(26), 9966-9977. https:// doi.org/10.1021/jf061478a.

Hidalgo, M., Sánchez-Moreno, C. and de PascualTeresa, S. (2010). Flavonoid-flavonoid interaction and its effect on their antioxidant activity. Food Chemistry, 121(3), 691-696. https://doi.org/10.1016/ j.foodchem.2009.12.097.

Khalil, M.I., Alam, N., Moniruzzaman, M., Sulaiman, S.A. and Gan, S.H. (2011). Phenolic Acid Composition and Antioxidant Properties of Malaysian Honeys. Journal of Food Science, 76(6), 921-928. https://doi.org/10.1111/j.17503841.2011.02282.x

Marasini, N., Yan, Y.D., Poudel, B.K., Choi, H.G., Yong, C.S. and Kim, J.O. (2012). Development and optimization of self-nanoemulsifying drug delivery system with enhanced bioavailability by BoxBehnken design and desirability function. Journal of Pharmaceutical Sciences, 101(12), 4584-4596. https://doi.org/10.1002/jps.23333.

Marquez, A., Dueñas, M., Serratosa, M.P. and Merida, J. (2012). Formation of vitisins and anthocyaninflavanol adducts during red grape drying. Journal of Agricultural and Food Chemistry, 60(27), 68666874. https://doi.org/10.1021/jf300998p

Muhammed, P. and Shamsi, M.S. (2016). Tibb-e-Nabawi - Medical guidance and teachings of Prophet Muhammad. India: Gulsan Printing Press.

Nazir, M., Arif, S., Khan, R.S., Nazir, W., Khalid, N. and Maqsood, S. (2019). Opportunities and challenges for functional food and medicinal beverages: current and future trends. Trends in Food Science and Technology, 88(2019), 513-526. https:// doi.org/10.1016/j.tifs.2019.04.011.

Patel, M.B., Shaikh, F., Patel, V. and Surti, N.I. (2017). Application of simplex centroid design in formulation and optimization of floating matrix tablets of metformin. Journal of Applied Pharmaceutical Science, 7(4), 23-30. https:// doi.org/10.7324/JAPS.2017.70403

Poyrazoğlu, E., Gökmen, V. and Artik, N. (2002). Organic acids and phenolic compounds in pomegranates (Punica granatum L.) grown in Turkey. Journal of Food Composition and Analysis, 15(5), 567-575. https://doi.org/10.1016/S0889-1575 (02)91071-9.

Rahim, N.F.A., Muhammad, N., Abdullah, N., Talip, B.A. and Dusuki, N.J.S. (2018). Optimization of the antioxidant properties of the polyherbal formulations. Journal of Advanced Research in Fluid Mechanics and Thermal Sciences, 50(1), 16-25.

Rahmani, A.H., Aly, S.M., Ali, H., Babiker, A.Y. and Srikar, S. (2014). Therapeutic effects of date fruits (Phoenix dactylifera) in the prevention of diseases via modulation of anti-inflammatory, antioxidant and antitumor activity. International Journal of Clinical and Experimental Medicine, 7(3), 483-491.

Ramamoorthy, P. and Bono, A. (2007). Antioxidant activity, total phenolic and flavonoid content of Morinda citrifolia fruit extracts from various extraction processes. Journal of Engineering Science and Technology, 2(1), 70-80. https:// doi.org/10.1.1.582.1056.

Saifullah, M., Yusof, Y.A., Chin, N.L. and Aziz, M.G. (2016). Physicochemical and flow properties of fruit powder and their effect on the dissolution of fast dissolving fruit powder tablets. Powder Technology, 301, 396-404. https://doi.org/10.1016/ j.powtec.2016.06.035

Sheikh, D.K. and Dixit, A.K. (2015). Plants in the Holy Quran: A Look. World Journal of Pharmacy and Pharmaceutical Sciences, 4(8), 715-738.

Slatnar, A., Klancar, U., Stampar, F. and Veberic, R. (2011). Effect of drying of figs (Ficus carica L.) on the contents of sugars, organic acids, and phenolic compounds. Journal of Agricultural and Food Chemistry, 59(29), 11696-11702. https:// doi.org/10.1021/jf202707y

Sun-Waterhouse, D. (2011). The development of fruitbased functional foods targeting the health and wellness market: A review. International Journal of Food Science and Technology, 46(5), 899-920. https://doi.org/10.1111/j.1365-2621.2010.02499.x 
Ververidis, F., Trantas, E., Douglas, C., Vollmer, G.,

Kretzschmar, G. and Panopoulos, N. (2007).

Biotechnology of flavonoids and other phenylpropanoid-derived natural products. Part I: Chemical diversity, impacts on plant biology and human health. Biotechnology Journal, 2(10), 12141234. https://doi.org/10.1002/biot.200700084

Wass, J.A. (2001). Design-Expert 6.0. Biotech Software and Internet Report, 2(2), 71-73. https:// doi.org/10.1089/152791601750193733 